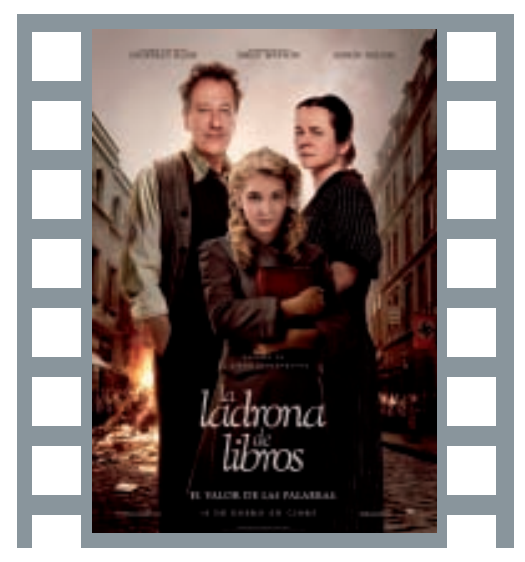

\section{ficha têcnica}

Título original: La ladrona de libros

Nacionalidad: Estados Unidos, Alemania

Dirección: Brian Percival

Guión: Michael Petroni

Producción: Fox 2000 Pictures

Año: 2013

Interpretación: Sophie Nélisse (Liesel); Geoffrey Rush (Hans); Emily Watson (Rosa); Nico Liersch (Rudy); Ben Schnetzer (Max); Barbara Auer (Ilsa Hermann)

Música: John Williams

Fotografía: Florian Ballhaus

Género: Drama, bélico

Duración: 131 minutos

Distribución: 20 ${ }^{\text {th }}$ Century Fox

Página oficial: http://www.laladronadelibros.es

Premios:

2014: Oscar: nominada a mejor banda sonora. Globos de Oro: nominada a mejor banda sonora. BAFTA: nominada a mejor banda sonora. Satellite Awards (International Press Academy): nominada a mejor actriz de reparto (Emily Watson) y mejor banda sonora. Critics' Choice Movie Award: nominada a mejor intérprete joven (Sophie Nélisse) AACTA International Award: nominada a mejor actor secundario (Geoffrey Rush).

\title{
La ladrona de libros
}

"Leer es ir al encuentro de algo que está a punto de ser y aún nadie sabe qué será"

(Italo Calvino)

Ana Iria García Rivero y Carmen Pereira Domínguez

lazarivero@hotmail.com y mcdguez@uvigo.es

\section{La historia}

Liesel Mamminger, una niña judía de nueve años, es adoptada por una familia obrera alemana durante la Segunda Guerra Mundial. Ayudada por Hans, su padre adoptivo, Liesel aprende a leer y adquiere una auténtica pasión por la lectura. Contando con el consentimiento de la mujer del alcalde, Liesel entra a hurtadillas en su biblioteca privada para coger libros prestados, cuyas historias comparte con Max, un judío que vive oculto en el sótano de su casa. Inmersa en un contexto histórico Ileno de violencia, injusticia y falta de libertad en el que Hitler gana cada vez más adeptos, el poder de la imaginación y el valor de las palabras se convierten para Liesel en una manera de escapar de los tumultuosos eventos que la rodean.

\section{Temas}

Adopción

Comunicación

Derechos Humanos

Duelo

Educación artística

Educación emocional

Educación familiar

Fomento y pasión por la lectura

Habilidades sociales

Muerte

Nazismo

Segunda Guerra Mundial

\section{Valores}

Amor

Amistad

Convivencia pacífica

Esperanza

Generosidad

Gratitud

Ilusión

Felicidad

Lealtad

Libertad de pensamiento y expresión

Tolerancia

Solidaridad

Superación

\section{(ִ.) Antes de ver la película}

1. Buscamos en Internet carteles propagandísticos utilizados por el régimen fascista en la Alemania de los años 30, así como fotografías que reflejen situaciones reales vividas durante el Holocausto. Analizamos y comentamos dichas imágenes desde un punto de vista denotativo y connotativo. Para cada sentimiento negativo o contravalor que se nos ocurre pensamos en su valor correspondiente (por ejemplo: injusticia versus justicia) y creamos una nube de palabras en www.tagxedo.com.

2. Nos distribuimos en varios grupos para rastrear las raíces del fascismo Europeo, su evolución y consecuencias. Seguidamente cada grupo elabora un póster digital a través de www.glogster.com con la información recabada, con el objetivo de conocer en profundidad el contexto histórico en el que se desarrolla el film.
3. Valoramos el papel que juega la discriminación racial y la violencia en el discurso y práctica fascista.

4. Elaboramos un glosario que contenga una breve definición de los siguientes conceptos: "antisemitismo", "anticomunismo", "xenofobia", "racismo", "homofobia", "nazismo", y "pangermanismo". Posteriormente reflexionamos y debatimos sobre los aspectos que contraponen el fascismo a la democracia, determinando de qué manera cada uno de ellos respeta y protege o niega y ataca los derechos humanos.

5. Buscamos información sobre Markus Zusak y la obra La ladrona de libros.

6. ¿Comentad qué otras lecturas conocéis sobre esta temática?

7. ¿Recordáis qué películas habéis visto vinculadas a estos acontecimientos? Averiguar en Internet y comprobaréis cómo en esta revista hemos trabajado algunas de ellas. 


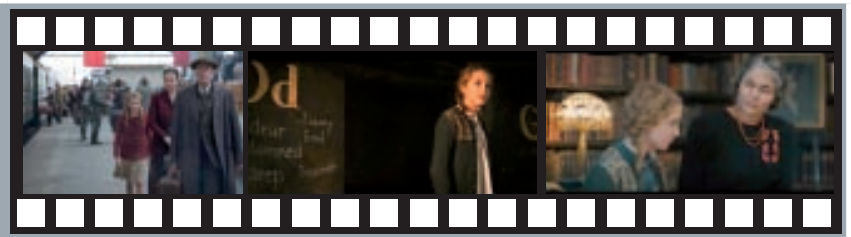

1.1. Liesel viaja en tren con su madre y su hermano, quien fallece antes de llegar a su destino. La madre de Liesel desaparece de escena tras el funeral. La niña ha sido dada en adopción. Mientras es trasladada en coche a su nuevo hogar, la enfermera que la acompaña le dice: "Se habría quedado contigo si hubiera podido. Lo sabes, iverdad?" (4'05").

1.2. La niña conoce a sus nuevos padres (4'38'). Rosa Hubermann se queja de que sólo les hayan traído a Liesel y no a los dos hermanos: "Nos prometieron dos niños y dos subsidios". "Culpo a su madre [...]. Lo que dicen sobre los comunistas es cierto: son sucios y estúpidos". Hans replica: "Rosa, no puedes culpar al niño por morir" y se dirige a Liesel para que baje del coche, tratándola de "su Majestad".

1.3. De noche, un miembro del ejército nazi llama a la puerta de los Vanderburg. Fuera, la guardia alemana comete atrocidades. Se trata de un buen amigo de la familia que viene a brindarles su ayuda. "Escuchad. Sólo puedo esconder a uno" (19'15"). La madre de Max insiste en que sea su hijo quien se salve. Él accede finalmente y, mientras la abraza con fuerza, le susurra: "Perdóname".

1.4. Liesel acude a la mansión de los Hermann para entregar la ropa que Rosa les ha lavado y planchado. Ilsa, la mujer del alcalde, reconoce inmediatamente a la niña (la había visto coger un libro de la hoguera tras el discurso de su marido en la plaza del pueblo). Le pregunta si le gustan los libros y la invita a entrar en su biblioteca: "Puedes venir siempre que quieras" $\left(50^{\prime 2} 20^{\prime \prime}\right)$. La segunda vez que coinciden, Ilsa le habla de su hijo Johann, desaparecido en combate durante la Primera Guerra Mundial: "A él le encantaba leer..., y era valiente, como tú. Este lugar es él" (52'41").

1.5. Es Navidad. Liesel coge nieve de la calle y la lleva al sótano para enseñársela a Max. Después de jugar con ella, hacen un muñeco y se sientan en torno a él mientras escuchan villancicos que Hans toca con su acordeón (1h.05'46"). Rosa afirma que es lo más ridículo que ha hecho en toda su vida, y Hans le responde: "Y mira lo feliz que estás". Liesel, en cambio, asegura: "Ésta es mi mejor Navidad".

1.1. Observamos esta secuencia en la que Liesel está con su familia biológica. Reflexionamos sobre los motivos que llevaron a esta mujer a entregar a sus hijos. ¿Cómo afecta este hecho a la protagonista?

1.2. Describimos a los padres adoptivos de Liesel en las primeras escenas. ¿A quién de los dos atribuimos los rasgos de dulzura y sensibilidad? Nos fijamos en cómo Rosa y Hans transgreden los estereotipos de género. Comparamos la relación de Liesel con cada uno de ellos al principio y al final de la película. ¿Cómo evoluciona Rosa a lo largo del film? ¿Cómo favorece la entrada de Liesel en su vida a esta transformación?

1.3. ¿Cuál es la situación familiar de Max? Observamos la actitud de su madre. ¿Qué sentimientos la mueven a tomar esa decisión? ¿Qué haríamos en su estado? ¿Y en la de Max? Analizamos el comentario de La Muerte, el narrador de esta historia, sobre este momento clave en la vida de Max y en cómo le afecta.

1.4. Nos aproximamos al personaje de Ilsa Hermann. ¿En qué sentido le recuerda Liesel a su hijo? ¿Qué valor simbólico tiene esta biblioteca para ella. En cuanto a la niña, ¿qué significa este espacio? Nos fijamos en su cara de estupefacción al observar tanta belleza y la dulzura con la que toca los libros que reposan en la estantería.

1.5. Visualizamos la escena navideña en el frío sótano de los Hubermann (1h.05'45") y explicamos la sensación que nos trasmite de calidez. Nos ponemos en la piel de cada uno de estos personajes y describimos cómo se sienten. ¿Podemos decir que constituyen una familia a pesar de que no los unen lazos de sangre? ¿Qué es entonces lo que los mantiene unidos? Reflexionamos sobre la importancia de la familia y los valores que en ella se forjan. ¿Qué nos aporta nuestra familia y qué le aportamos a ella?

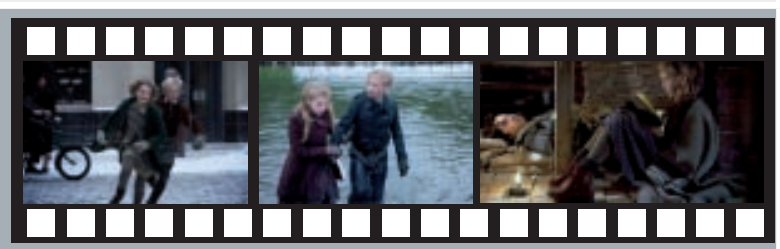

2.1. Desde el primer momento que Rudy ve a Liesel, éste decide no separarse más de ella. Progresivamente entablan una bonita amistad que comienza cuando él la va a buscar a casa para acompañarla en su primer día de colegio: "Pensé que necesitarías un amigo"(11'02"). Desde entonces se hacen inseparables, en ocasiones se comunican a través de un lenguaje no verbal ("¿Un escupitajo es sí y dos no?", 10'44") y se guardan secretos (la costumbre de Liesel de coger libros prestados, o el hecho de que ocultan a un judío en el sótano). Su complicidad es evidente cuando ambos caminan hacia casa después de que Rudy se haya sumergido en el río para recuperar el diario de Liesel (1h.17"40"). En la última ocasión que los vemos juntos escuchamos al muchacho: "Necesito decírtelo. Te quiero", a lo que Liesel responde llorando desconsoladamente: "¡Rudy despierta! ¡Rudy bésame!" (1h.58'45”).

2.1. Nos fijamos en las distintas escenas en las que Rudy y Liesel aparecen juntos y detallamos su relación. Valoramos el apoyo mutuo que se brindan en momentos difíciles y cómo crecen y maduran, hasta comprender como Hitler y su política está cambiando el rumbo de sus vidas. Reparamos en su último encuentro, tras el fatídico bombardeo. ¿Estos personajes son un ejemplo de lo que es "el primer amor"? 
2.2 Desde que Liesel conoce a Max, la niña se siente inmediatamente ligada a él. Sus primeras conversaciones nos testimonian de todo lo que tienen en común (39'48" y 43'30"). Con el paso del tiempo están más unidos, y Max se convierte en un verdadero maestro: “ ¿Puedes describirme que día hace hoy? [...] Haz tuyas las palabras [...] Si tus ojos pudieran hablar, ¿qué dirían?" (57'56"). Antes de su despedida asistimos a una escena enternecedora (1h. 34'08"): Max decide abandonar la casa de los Hubermann para no ponerlos en peligro. Liesel afirma: "Pero tú eres mi familia [...] No puedo perder a nadie más". Max le responde: "A mí no me vas a perder, Liesel. Siempre vas a poder encontrarme en tus palabras. Ahí continuaré vivo".
2.2. ¿Qué comparten Liesel y Max, además de la protección de los Hubermann? ¿De qué manera los unen estos hechos? ¿Podemos decir que Max es una especie de hermano mayor para Liesel? ¿Qué aprende de él?

\section{(3)}

Los contravalores del nazismo

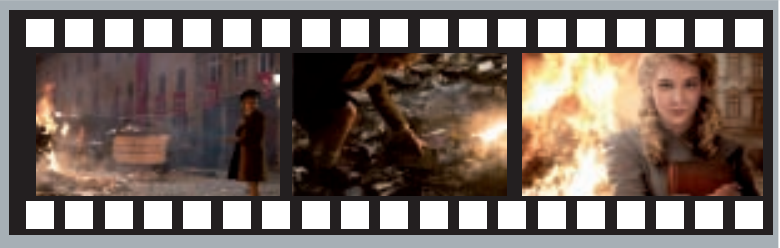

3.1. Mientras se escucha la canción entonada por los niños del coro vemos una sobrecogedora escena ambientada en la "Noche de los Cristales Rotos" o Kristallnacht (18'37").

3.2. El atleta de origen afroamericano, Jesse Owens, es el ídolo de Rudy. Un día, el muchacho decide pintarse la cara y los brazos de negro mientras entrena, imaginando que es el famoso Owens $\left(23^{\prime} 02^{\prime \prime}\right)$. Un hombre lo descubre y lo lleva a casa enfurecido. Allí, su padre lo limpia inmediatamente: "Hijo, no puedes ir por ahí pintado de negro". Rudy pregunta: ¿Por qué no?, su padre dice: "Porque no debes querer ser negro". Rudy no lo comprende, insiste y su padre zanja la discusión: "Porque lo digo yo".

3.3. En la película aparecen dos escenas en las que Liesel y otros niños entonan cánticos: la primera en la escuela (17'54") y la segunda durante la quema de libros $\left(28^{\prime} 20^{\prime \prime}\right)$.

3.1. ¿Quiénes están siendo víctimas de la ideología nazi? ¿Con qué palabras exponemos estas imágenes? ¿Qué nos suscitan?

3.2. ¿Qué características del deportista valora Rudy y cuáles rechaza su padre? Nos fijamos en la falta de argumentos de éste para explicar a su hijo por qué no debe querer ser negro.

3.3. Comparamos ambas escenas: Ios ojos ilusionados de Liesel mientras canta en el colegio, ignorando el significado encriptado en la letra de la canción, y su mirada atónita cuando comprende ante la hoguera el verdadero sentido del discurso nazi, y cómo las palabras de Hitler tienen el poder de controlar ideológicamente al pueblo alemán.

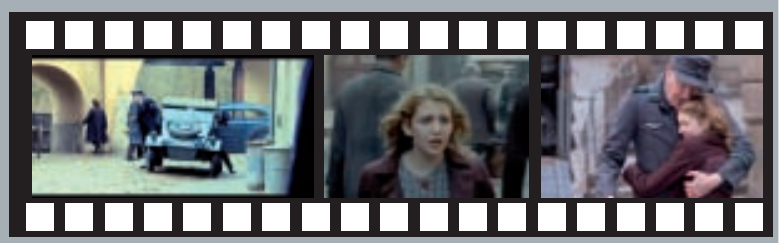

4.1. "El valor de las palabras" no es sólo el lema de La ladrona de libros, sino que, como explica Hans Hubermann, "una persona es tan buena como lo sea su palabra" (37'26"), y por ello debemos cumplir siempre nuestras promesas. El acordeón que toca Hans le recuerda a diario la deuda que tiene con Erik Vandenburg, el hombre que dio su vida por salvarlo.

4.2. Hans trata de defender a un vecino acusado de ser judío (1h.31'10"): "Por favor, conozco a ese hombre de toda la vida. Le conocemos. Es una buena persona". Hans es agredido por uno de los guardias ante la mirada insulsa del resto del vecindario. Max le explica a Liesel lo que Hans supuestamente ha hecho mal: "Le ha recordado a la gente su humanidad" (1h.33'16").

4.3. Liesel se cruza en la calle con un grupo de judíos que está siendo deportado (1h.48'00"). Por un momento cree ver a Max entre ellos y lo llama, mientras repite entre susurros: "No quiero olvidarte". Un guardia la empuja violentamente, pero ella insiste en encontrar a su amigo
4.1. Apreciamos el paralelismo entre el primer capítulo del libro que Liesel ha cogido en la hoguera, "La llegada del hombre desconocido", y el hecho que interrumpe su lectura: la irrupción de Max en sus vidas. Comprobamos cómo Hans no duda en ayudar al hijo de su difunto amigo Erik cuando éste lo necesita. Estimamos como Rosa, a pesar del miedo, apoya a su marido, aún sabiendo que si esconde a este chico judío en su sótano implica ponerlos a ellos mismos en peligro.

4.2. Comparamos la reacción de Hans con la del resto de vecinos. ¿Qué valores destacamos del primero y qué contravalores representan a los segundos? Meditamos sobre las ideas de "responsabilidad compartida" y "resistencia pasiva" en el contexto del nazismo.

4.3. ¿Es consciente Liesel del peligro que corre si la ven relacionarse con un judío? ¿Qué sentimientos la mueven a actuar así? 
4.4. En la siguiente escena vemos como Rosa cura las heridas que Liesel se ha hecho en la mano y refiriéndose a su acto heroico dice: "Eres igual que tu padre, isabes?" (1h.49'19").
4.4. Pensamos sobre cómo Liesel posee los mismos principios éticos que su padre adoptivo Hans, un ejemplo de honradez y lealtad. ¿De qué manera creéis que la educación que reciben los hijos influye en la configuración de su personalidad?

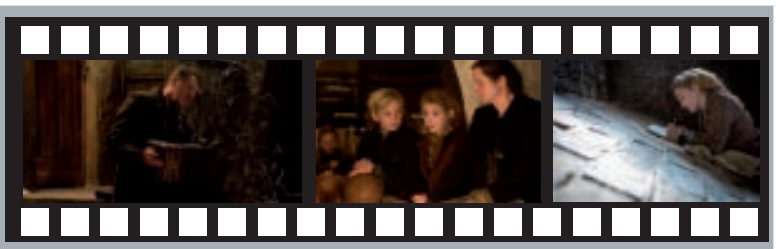

5.1. Observamos como Max utiliza las pinturas de Hans para teñir de blanco las páginas de un libro titulado Mein Kampf (1h.02'23"). Es el regalo de Navidad de Liesel (1h.07'00"): "Las palabras son vida, Liesel. Todas esas páginas en blanco son para que las llenes"

5.2. Durante el primer bombardeo, todo el vecindario se refugia en el sótano de una de las casas del barrio. Mientras el terror se apodera de ellos, Hans toca una hermosa canción con su acordeón (1h.29'30"). En el siguiente bombardeo, Liesel observa la silla vacía de su padre y se lanza a contar una historia (1h.44'33").

5.3. Sólo hay un momento en toda la película en el que Liesel toca el acordeón de su padre: tras el último bombardeo que se lleva por delante la vida de muchos de sus seres queridos. Sus dedos frágiles acarician las teclas y éstas emiten un leve sonido. Liesel es rescatada de entre los escombros (1h.56'09").
5.1. Mein Kampf en alemán significa "mi lucha", es obra de Adolf Hitler, quien combina el género autobiográfico con una exposición de la ideología nazi. ¿Cómo interpretamos el hecho de que sea precisamente este libro sobre el que Liesel escribe su propia historia? ¿Consideramos que el color blanco de las hojas es simbólico?

5.2. Comparamos el poder tranquilizador de la música y la literatura en estas escenas. ¿De qué modo ayudan estas dos artes a los vecinos de Himmelstrasse ("El Cielo") a olvidar el horror que está aconteciendo tan cerca? Debatimos sobre lo irónico que resulta el nombre de la calle donde viven los Hubermann y lo que ocurre en ella finalmente.

5.3. Reflexionamos sobre como la música, que simbólicamente había salvado a sus vecinos de caer en las garras del miedo durante los bombardeos, salva literalmente a Liesel. Miramos también como en la última escena de la película el acordeón de su amado padre ocupa un lugar especial en el comedor de su casa, protegido ahora por una vitrina.

\section{Aleunas curiosidades de interês}

1. La protagonista canadiense, Sophie Nélisse, es conocida por su briIlante interpretación en Profesor Lazhar (Philippe Falardeau, 2011). Además es una destacada gimnasta.

2. La música de la película está compuesta por John Williams, reconocido compositor y director de orquesta estadounidense. Es artífice de famosas y premiadas bandas sonoras como: Tiburón, E.T. El extraterrestre, Superman, La lista de Schindler, Indiana Jones, Parque Jurásico, Harry Potter, Memorias de una Gheisa, entre otras.

3. Con La Ladrona de Libros, el director inglés Brian Percival, pretendió acercar el tema del Holocausto a las jóvenes generaciones (http://www2.esmas.com/entretenimiento/cine/718165/no-facilrodar-ladrona-libros/).

\section{Actividades de experiencia, reflekiôn y acción en común}

1. Las fuerzas nazis de la SA protagonizan "La noche de los cristales rotos". Nos informamos en Internet sobre este hecho histórico, lo exponemos y debatimos en el aula.

2. Leemos parte del discurso pronunciado durante la quema de libros y reflexionamos sobre el concepto de "control ideológico" y su contraposición a la "libertad de expresión y pensamiento":

Durante esta revolución socialista nacional, por mucho que nuestra nación prospere, no debe decaer nuestra determinación para limpiarnos moralmente e intelectualmente desde dentro. Educación, teatro, películas, literatura, la prensa: estos son los pilares de apoyo que dan forma a la personalidad única de nuestra nación; y ese es el porqué nos hemos reunido aquí esta noche: para liberarnos de cualquier suciedad intelectual. Exterminaremos la enfermedad que ha infectado Alemania durante los últimos veinte años. Destruiremos por completo las cadenas que se forjaron para esclavizarnos. Lucharemos contra nuestros enemigos aunque eso signifique la guerra [...].
3. El libro que Liesel coge de la hoguera es El hombre invisible, de H.G. Wells. Nos documentamos sobre este escritor, el argumento del libro y los motivos de su censura.

4. Como hemos visto en la película, a Liesel y Max les encanta leer. ¿Cuáles son nuestros libros favoritos? Los traemos al aula para compartir un breve fragmento con nuestros compañeros y compañeras. ¿Qué es lo que más nos gusta de estos libros y por qué?

5. Mientras que a Rudy le apasiona jugar al fútbol y correr, Hans es un amante de la música y de su inseparable acordeón. Pensamos en nuestro pasatiempo favorito y explicamos cómo nos hace sentir.

6. Uno de los valores más importantes que detectamos en La ladrona de libros es el de la amistad. En nuestra vida personal, ¿qué características apreciamos en una amiga 0 amigo?

7. Valoramos la película: título, guión, interpretación, diálogos, planos, encuadre, ambientación, color, música, efectos sonoros, mensaje..., ¿qué destacamos de ella y qué enseñanzas nos ofrece? 